\section{US in grip of West Nile virus}

While America pours billions into bioterrorism research based on the hypothetical threat posed by some pathogens, states across the country are in the grip of an emerging disease-infection with the mosquito-borne West Nile virus. Last month, concerns about the disease reached new levels when it was discovered that the virus can be transmitted through organ transplantation and possibly through blood transfusion.

As Nature Medicine went to press, this season's tally stood at 954 cases and 43 deaths. Daily counts are posted on the website of the Centers for Disease Control and Prevention (CDC) at http://www. cdc.gov/od/oc/media/wncount.htm. This compares with 142 cases, including 18 deaths, between 1999 and 2001, since which time the virus has been spreading rapidly from New York to the Eastern seaboard, the southeast and Midwest. In addition, the first case of West Nile virus contracted west of the Rocky Mountains has come to light: a Los Angeles woman tested positive for the virus which was not predicted to reach California until 2004.

Officials in Florida and Georgia are investigating the possibility that the virus is transmitted through organ transplantation, after four people who received organs from the same donor contracted the disease. Although the CDC's Lyle Peterson has pronounced the donor the most likely source of infection, Ed Thompson, a Mississippi health officer, is playing down the possibility that blood supplies are infected with the virus-a Mississippi woman tested positive four weeks after receiving blood during surgery.

CDC officials are insisting that the risk of contracting West Nile from a blood transfusion is low. Unlike HIV or hepatitis $\mathrm{C}$ infection, people infected with West Nile are viremic for only a few days. In addition, blood banks screen out anyone who has had a recent fever. Peterson told reporters, "The medical benefit of getting blood or organs far outweighs any potential risk of getting West Nile virus transmission from blood or organs."

West Nile virus, a flavivirus closely related to St. Louis encephalitis virus, is endemic in parts of Africa, Asia, Europe and Australia. Although mosquitoes are the vector for the virus, birds are instrumental in the spread of the virus, acting both as a viral reservoir and as the mode of geographical spread. The first appearance of West Nile in New York in 1999 was traced to a virus isolated from a goose in Israel (Science 286, 2333; 1999), but new reports show that the virus has now been found in dead birds of 110 species.

While testing for virus-specific neutralizing antibody is the gold standard for diagnosing the disease, researchers at the CDC's Division of Vector-Borne Diseases at Fort Collins, have developed a rapid, PCR-based assay for the virus (J. Clin. Microbiol. 39, 4506; 2001). This test takes only three hours, as opposed to a week for the antibody test, and is being used to test blood from the transfusion case. However, should large-scale screening of blood from blood banks be necessary, a less expensive test would need to be developed, according to Robert Lanciotti of the CDC.

Infection with West Nile virus produces no symptoms $80 \%$ of the time. The remaining cases of infection result in a mild, flu-like disease, and in one out of 140 cases, patients develop a serious neurological illness such as encephalitis or meningitis (Lancet 358, 261; 2001). Given this ratio of serious-to-total cases, estimates suggest that over 100,000 Americans could be infected with the virus.

Several groups are developing suitable vaccines. The British company Acambis is to enter clinical trials with a chimeric vaccine in which the envelope genes of a yellow fever vaccine are replaced with the corresponding genes of the West Nile virus. Using a similar approach, researchers at NIAID have created a chimeric West Nile virus vaccine using the backbone of the Dengue virus, which is still in preclinical trials (PNAS 99, 3036; 2002).

Laura Defrancesco, Pasadena

\title{
Preparedness panel meets
}

The Council on Public Health Preparedness, created to advise the US Department of Health and Human Services' Secretary Tommy Thompson on how best to prepare for and defend the country against bioterrorist attacks, has held its first meeting. The 21-member council set out to prioritize counter-terrorism measures and recommend how to achieve these goals. Anti-bioterrorism research was high on the agenda.

"In the whole area of biodefense, there is incredible need for research-the cupboard is rather empty," says Council member Frederick Murphy, professor at the University of California, Davis School of Veterinary Medicine. Anthony Fauci, director of the National Institute of Allergy and Infectious Diseases (NIAID), presented new areas for NIAID-funded bioterrorism research, and described the construction of new facilities suitable to work with category A pathogens such as anthrax, botulism, tularemia, plague, smallpox and ebola.

The Council identified three crucial areas of study. The "highest research priority," according to Council member Gail Cassell, vice president for Scientific Affairs at Eli Lilly, is the development of relevant animal models to test therapeutic compounds under study. US research is "severely lacking" in this area, says Cassell. Other priorities include studying the pathogenic characteristics of infectious agents themselves, and hosts responses to them. Finally, the development of broad-spectrum antiviral drugs, antibiotics and immune modulators must be accelerated. Other priorities include "better surveillance to detect outbreaks, either natural or manmade," she says. The Council also acknowledged the need to educate the public, government officials and emergency services.

The Council's role is strictly advisory; it has no official power over governmental policymaking or implementation. However, it is expected to be a strong influence on the direction of spending of the new $\$ 1.75$ billion for bioterrorism research at NIAID proposed for FY03. Despite the fact that the new NIAID monies represent the single largest funding increase ever disbursed by the NIH, Cassell cautions the public against impatience and high expectations. The development of any new vaccine, antibiotic or antiviral therapy takes 5-7 years at a minimum. She believes it is important to appreciate that while the increase in NIAID funding is quite significant, it is still "only a drop in the bucket compared to the cost of developing and producing effective compounds."

The Council will meet three or four times a year to reassess the state of the country's preparedness for bioterrorist attacks and reprioritize goals if necessary. Future projects include increased recruitment of young researchers into bioterrorism research. "There are lots of brilliant young scientists...out there, but recruiting them into this particular subject area will be a challenge," says Murphy, who attributes this to an unclear career path, no specific research training programs and peer pressure.

CAITLIN SMith, OREgON 